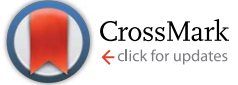

Cite this: RSC Adv., 2017, 7, 13383

Received 11th January 2017

Accepted 14th February 2017

DOI: 10.1039/c7ra00433h

rsc.li/rsc-advances

\title{
Nitrogen-doped porous activated carbon derived from cocoon silk as a highly efficient metal-free electrocatalyst for the oxygen reduction reaction $\uparrow$
}

\begin{abstract}
Peng Fu, ${ }^{a}$ Lihua Zhou, ${ }^{* a}$ Lihua Sun, ${ }^{a}$ Baohua Huang ${ }^{a}$ and Yong Yuan*b
Heteroatom-doped porous carbon has attracted considerable research interest due to its effective catalytic activity towards the oxygen reduction reaction (ORR). In this study, nitrogen-doped porous activated carbon (PAC) is fabricated via a facile heat-treatment and chemical activation of cocoon silk in an inert gas atmosphere. The prepared PAC exhibits excellent ORR catalytic performances with the half-wave potential of $-0.13 \mathrm{~V}$ and an onset potential of $+0.03 \mathrm{~V}$ vs. $\mathrm{Ag} / \mathrm{AgCl}$, which match the $\mathrm{Pt} / \mathrm{C}$ catalyst and are superior to various other reported biomass derived metal-free carbon catalysts. This catalytic proficiency is attributed to the plentiful electronegative $N$ atoms within the carbon lattice, large surface area and high porosity. The PAC also exhibits high stability, durability and an effective tolerance effect to methanol crossover. In addition, the as-prepared PAC shows remarkable feasibility as a cathodic catalyst for microbial fuel cells (MFCs). This study provides a new approach for the synthesis of metal-free carbon nanomaterials derived from natural materials, and broadens the design for the fabrication of ORR catalysts.
\end{abstract}

\section{Introduction}

The oxygen reduction reaction (ORR) is a critical reaction occurring at the cathode in new energy generation technologies, such as fuel cells and metal-air batteries. ${ }^{1-3}$ However, the sluggish reaction kinetics of the ORR significantly hinder the performance of these energy generation technologies. ${ }^{4-6}$ Active catalysts are usually used to accelerate the reaction rate of the ORR. Thus far, platinum (Pt)-based materials have been considered as the most efficient catalysts to facilitate the ORR process by catalyzing $\mathrm{O}_{2}$ into $\mathrm{H}_{2} \mathrm{O}$ via a four-electron pathway with a lower over-potential and higher current response. ${ }^{7-9}$ However, the wide commercialization of Pt-based catalysts is greatly impeded by their high cost, low natural abundance, poor stability and low poisoning tolerance. ${ }^{\mathbf{8}, 10,11}$ Thus, it is highly desirable to develop alternatives to Pt-based catalysts to drive the boom in new energy generation technologies.

Recently, N-doped porous carbon materials have been investigated as ideal candidates to replace the Pt-based catalysts toward the ORR due to their large specific surface areas, good

${ }^{a}$ Institute of Natural Medicine and Green Chemistry, School of Chemical Engineering and Light Industry, Guangdong University of Technology, Guangzhou, 510006, P. R. China.E-mail: qhzhoulh@gdut.edu.cn

${ }^{b}$ Guangdong Key Laboratory of Integrated Agro-environmental Pollution Control and Management, Guangdong Institute of Eco-Environmental Science and Technology, 510650, P. R. China. E-mail: yuanyong@soil.gd.cn

$\dagger$ Electronic supplementary information (ESI) available. See DOI: 10.1039/c7ra00433h electrical conductivities, and high chemical stability. ${ }^{12-14}$ Soft- or hard-template carbonization methods have been mainly used to prepare heteroatom-doped porous carbon catalysts using Cand $\mathrm{N}$-enriched chemicals as precursors. ${ }^{15,16}$ However, relatively expensive and harmful $\mathrm{C} / \mathrm{N}$ precursors are usually used, and tedious and time-consuming procedures are involved in the production of carbon catalysts. In this regard, previous studies have shown the simple conversion of natural N-enriched materials into $\mathrm{N}$-doped carbon materials via facile heattreatment, which represents a promising potential alternative to the tedious and expensive methods. Numerous $\mathrm{N}$-doped carbon nanomaterials have been produced from moss, microorganisms, Typha orientalis, Amaranthus, okara, and bamboo fungus, which have shown significant potential as catalysts toward the ORR. ${ }^{17-22}$ Cocoon silk (CS), which is known as a filamentous natural proteinic fiber, is a representative natural $\mathrm{N}$ enriched material. ${ }^{23-25}$ Raw CS is made of sericin and fibroin. The former covers the surface of CS and can be removed through heat-treatment, and the latter, which contains numerous types of amino acids such as glycine, alanine and serine, accounts for almost $75 \%$ of the raw $\mathrm{CS}^{.26,27} \mathrm{CS}$ can severe as an effective precursor material to produce carbon catalysts for the ORR. For example, Iwazaki et al. successfully prepared activated carbon with high catalytic activity for the ORR via the carbonization and stream-activation of $\mathrm{CS}^{28,29}$ however, the steam activation process is relatively complex and timeconsuming. In addition, Wang et al. reported CS-derived graphene-like carbon with high catalytic activity for the ORR. ${ }^{30}$ However, they used chemical vapor deposition (CVD) methods 
for pre-treatment, which are often very tedious and expensive because elaborate and precise vacuum-based fabrication is required. In this regard, it is important to develop mild preparation approaches with high-efficiency and easy operation procedures to prepare high-performance carbon nanomaterials from CS.

Herein, we present a highly-efficient, low-cost approach to prepare $\mathrm{N}$-doped porous carbon materials from natural CS fibers via a facile heat-treatment and chemical activation. The resulting activated carbon shows excellent catalytic activity and admirable stability for the ORR in alkaline media. The high ORR activity of the catalyst is attributed to its high surface area, hierarchical porous distribution and high content of nitrogen species. This preparation method provides a convenient utility of silk, and exhibits an effective approach to synthesize biomass derived carbonaceous nanomaterials.

\section{Experimental}

\subsection{Preparation of $\mathbf{N}$-doped PAC derived from cocoon silk}

First, cocoon silk was obtained from white cocoons that were boiled in water for $30 \mathrm{~min}$, followed by washing with distilled water and drying at $60{ }^{\circ} \mathrm{C}$ for $12 \mathrm{~h}$. Second, the silk was heat treated in an alumina crucible at $300{ }^{\circ} \mathrm{C}$ at a heating rate of $5{ }^{\circ} \mathrm{C}$ $\min ^{-1}$ under an $\mathrm{N}_{2}$ atmosphere for $1 \mathrm{~h}$. The resulting solid product was mixed with $\mathrm{ZnCl}_{2}$ at a ratio of $1 / 2\left(\mathrm{~g} \mathrm{~g}^{-1}\right)$ by grinding sufficiently for chemical activation. Finally, the mixture was carbonized in an alumina crucible at $800{ }^{\circ} \mathrm{C}$ at a heating rate of $5{ }^{\circ} \mathrm{C} \min ^{-1}$ under $\mathrm{N}_{2}$ atmosphere for $1 \mathrm{~h}$. The resulting black product was treated with a $2 \mathrm{~mol} \mathrm{~L}^{-1} \mathrm{HCl}$ solution under stirring for $12 \mathrm{~h}$, washed with distilled water, and finally dried at $60{ }^{\circ} \mathrm{C}$. For comparison, the chemically activated samples were carbonized in an alumina crucible at 600,700 and $900{ }^{\circ} \mathrm{C}$ under the same condition for $1 \mathrm{~h}$. These final porous activated carbon products were denoted as PAC- $T$, where $T$ is the final carbonized temperature. A control sample was directly carbonized at $800{ }^{\circ} \mathrm{C}$ without activation and denoted as DC-800.

\subsection{Structural characterization}

Field emission scanning electron microscopy (FE-SEM, S-4800, Hitachi, Ltd., Tokyo, Japan) was used to investigate the morphology and microstructure of the as-prepared products. Crystallite structures were determined by XRD (X'Pert Pro, Philips). Raman spectra were recorded on a LabRAM Aramis confocal microscope Raman spectrometer system (Renishaw Instruments, England). $\mathrm{N}_{2}$ adsorption-desorption isotherm measurements were performed at $300{ }^{\circ} \mathrm{C}$ for $8 \mathrm{~h}$ on a sorptometer (Model 1800, Carlo Erba Instruments, Italy). The pore size distribution (PSD) was calculated via the Barrett-JoynerHalenda (BJH) model and specific surface areas were calculated using the Brunauer-Emmett-Teller (BET) method. Surface chemical species were examined via X-ray photoelectron spectroscopy (XPS, Thermal Scientific ESCALAB 250Xi spectrometer, USA) and quantitative energy dispersive X-ray spectroscopy
(EDS) mapping by field emission scanning electron microscopy (FE-SEM, S-4800, Hitachi, Ltd., Tokyo, Japan).

\subsection{Electrochemical measurements}

Prior to electrochemical measurements, $2.0 \mathrm{mg}$ of PAC- $T$ was dispersed in a mixed solution of $200 \mu \mathrm{L}$ ethanol, $100 \mu \mathrm{L}$ distilled water and $10 \mu \mathrm{L}$ Nafion ( $5 \mathrm{wt} \%$ ) to prepare catalyst inks. A wellcleaned glassy carbon electrode (GCE, $5.0 \mathrm{~mm}$ in diameter) coated with $10 \mu \mathrm{L}$ of catalyst ink served as the working electrode, and an $\mathrm{Ag} / \mathrm{AgCl}$ electrode and Pt sheet were used as the reference and counter electrode, respectively. Cyclic voltammetry (CV) and linear sweep voltammetry (LSV) curves were obtained in an $\mathrm{O}_{2}$ and/or $\mathrm{N}_{2}$-saturated $0.1 \mathrm{~mol} \mathrm{~L}^{-1} \mathrm{KOH}$ solution at a scan rate of $10 \mathrm{mV} \mathrm{s}^{-1}$ in a conventional three-electrode cell connected to an electrochemical workstation (CHI660D, Shanghai Chenhua Instruments Co., China). Koutecky-Levich $(\mathrm{K}-\mathrm{L})$ plots at various electrode potentials were investigated using the LSVs, and the electron transfer numbers were calculated using the $\mathrm{K}-\mathrm{L}$ equation:

$$
\begin{aligned}
& j^{-1}=j_{\mathrm{k}}^{-1}+\left(B \omega^{0.5}\right)^{-1} \\
& B=0.62 n F\left(D_{\mathrm{O}_{2}}\right)^{\frac{2}{3}} \nu^{-\frac{1}{6}} C_{\mathrm{O}_{2}}
\end{aligned}
$$

where $j$ and $j_{\mathrm{k}}$ are the measured and kinetic limiting current densities, respectively, $\omega$ is the rotation speed, $\mathrm{n}$ is the electron transfer number in the reduction of $\mathrm{O}_{2}, F$ is the Faraday constant $\left(F=96485 \mathrm{C} \mathrm{mol}^{-1}\right), D_{\mathrm{O}_{2}}$ is the diffusion coefficient of $\mathrm{O}_{2}$ in $0.1 \mathrm{~mol} \mathrm{~L}^{-1} \mathrm{KOH}, C_{\mathrm{O}_{2}}$ is the bulk $\mathrm{O}_{2}$ concentration in $0.1 \mathrm{~mol} \mathrm{~L}^{-1} \mathrm{KOH}$, and $\nu$ is the kinematic viscosity of the electrolyte.

\subsection{Microbial fuel cell (MFC) setup and operation}

The air-cathode, single-chamber MFC was set up as described by Zhou et al. ${ }^{14}$ Briefly, a carbon brush $(2.5 \mathrm{~cm}$ in both diameter and length) served as the anode, and the cathode was prepared by dispersing either the as-prepared carbon nanomaterials or $\mathrm{Pt} / \mathrm{C}$ on the catalytic layer of the cathodic carbon cloth. The catalyst dosage of the two materials was 2.0 and $0.5 \mathrm{mg} \mathrm{m}^{-2}$, respectively. The liquid volume of the MFCs was $28 \mathrm{~mL}$. The electrolyte was $1 \mathrm{~g} \mathrm{~L}^{-1}$ sodium acetate solution in $50 \mathrm{mmol} \mathrm{L}^{-1}$ phosphate buffer solution (PBS, $\mathrm{pH}=7.0$ ) contacting a $12.5 \mathrm{~mL}$ $\mathrm{L}^{-1}$ mineral and $5 \mathrm{~mL} \mathrm{~L}^{-1}$ vitamin solution. The voltages of the MFCs were recorded using a 40-channel voltage collection instrument with a $1 \mathrm{k} \Omega$ external resistance, and the polarization curves and individual potentials were constructed by discharging the cell with external loads of various resistance. All of the MFCs were operated in batch mode in a $30{ }^{\circ} \mathrm{C}$ incubator, and tests were conducted in triplicate.

\section{Results and discussion}

Fig. 1 exhibits the representative SEM images of the raw silk, DC-800 and PAC-800 samples. The fiber structure of the raw silk can be observed in Fig. 1a-c, which shows one-dimensional carbon fibers with a smooth surface and a diameter of about $10 \mu \mathrm{m}$. It should be noted that after carbonization, the heated 


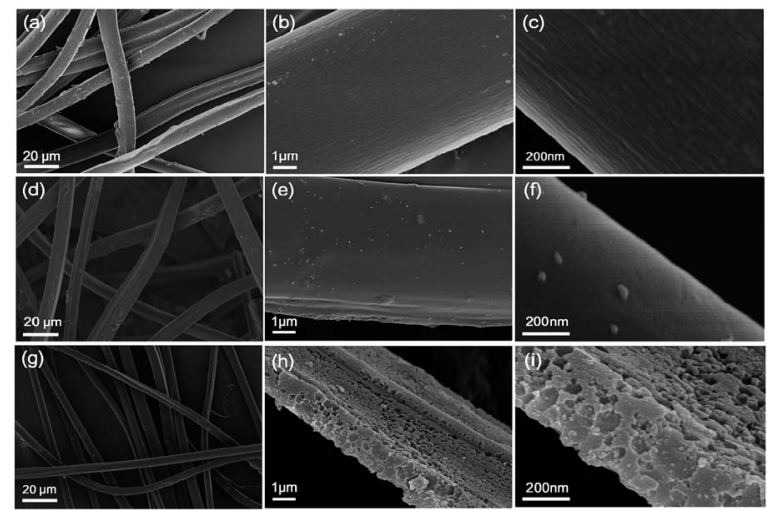

Fig. 1 Representative SEM images of the raw silk (a-c), DC-800 (d-f) and PAC-800 $(g-i)$ at various magnifications.

silk (DC-800) still maintains its continuous filament morphology (Fig. 1d-f), which suggests that the heat-treatment does not destroy the morphology of the raw silk..$^{31,32}$ However, it is worth noting that there are lots of visible micropores distributed on the surface of PAC-800. This can be explained by the chemical activation by $\mathrm{ZnCl}_{2}{ }^{31-34}$ The specific surface areas and the pore structure of the carbon materials were quantified by nitrogen adsorption-desorption measurement. Fig. 2(a and b) exhibits the $\mathrm{N}_{2}$ adsorption-desorption isotherms and pore size distributions (PSD) curves. All five samples show a typical type-I isotherm (Fig. 2a), which indicates the microporous nature of these materials. ${ }^{32,33}$ The surface areas of the samples are listed in Table S1, $\dagger$ where PAC-800 exhibits the highest BET surface area $\left(1273.8 \mathrm{~m}^{2} \mathrm{~g}^{-1}\right)$. The surface area of PAC-800 is significantly higher than that of DC-800 $\left(137.0 \mathrm{~m}^{2} \mathrm{~g}^{-1}\right)$, which demonstrates that the chemical activation procedure using $\mathrm{ZnCl}_{2}$ was effective in increasing the surface area of the CSderived carbon material. Fig. $2 \mathrm{~b}$ displays the PSD curves of the samples, which show that the pore size distribution range is mainly from 1 to $12 \mathrm{~nm}$, and the corresponding pore volumes
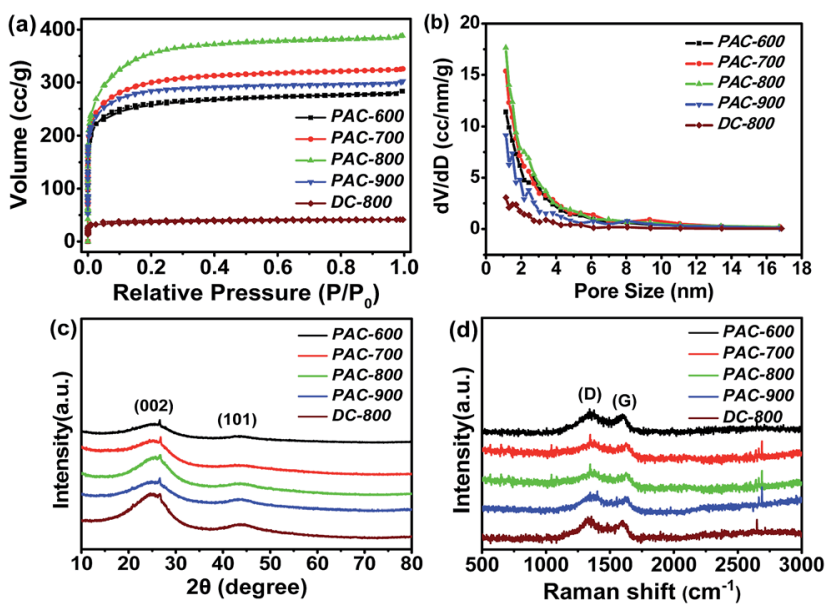

Fig. $2 \mathrm{~N}_{2}$ adsorption-desorption isotherms (a), pore size distributions (b), XRD patterns (c) and Raman spectra (d) of PAC-600, PAC-700, PAC-800, PAC-900 and DC-800. range from 0.06 to $0.60 \mathrm{~cm}^{3} \mathrm{~g}^{-1}$. The pore volumes of the activated samples became much larger with the increase in carbonization temperature from $600{ }^{\circ} \mathrm{C}$ to $800{ }^{\circ} \mathrm{C}$, however, it decreased significantly when the temperature increased from $800{ }^{\circ} \mathrm{C}$ to $900{ }^{\circ} \mathrm{C}$. As previously reported by Hu et al.,${ }^{33}$ when the carbonization temperature is higher than the melting point of $\mathrm{ZnCl}_{2}\left(283{ }^{\circ} \mathrm{C}\right)$, liquid $\mathrm{ZnCl}_{2}$ permeates into the interior of the carbon matrix, and contributes to the formation of a carbon framework. Furthermore, when the temperature is higher than the boiling point $\left(732^{\circ} \mathrm{C}\right)$, a severe interaction between the zinc compounds and carbon atoms occurs, resulting in the aromatization and widening of the atomic layers of the carbon as well as the formation of a porous structure in the carbon matrix. ${ }^{33,34}$ However, with a further increase in temperature, charring and aromatization of the carbonaceous material could result in dimensional contraction, subsequently leading to a decrease in the pore volume and specific surface area. ${ }^{35}$ PAC- 800 exhibits the highest BET surface area $\left(1273.8 \mathrm{~m}^{2} \mathrm{~g}^{-1}\right)$, the largest total pore volume $\left(0.6 \mathrm{~m}^{3} \mathrm{~g}^{-1}\right)$ and the largest pore diameter $(1.9 \mathrm{~nm})$, which suggest that the suitable carbonization temperature is $800{ }^{\circ} \mathrm{C}$.

For further structural characterization, these carbon materials were investigated using XRD and Raman spectroscopy. As shown in Fig. 2c, all five samples exhibit two major diffraction peaks at $24^{\circ}$ and $44^{\circ}$, which are assigned to the (002) and (101) diffraction planes of hexagonal graphite, respectively. ${ }^{36-39}$ The interlayer spacing $(d)$ and crystallite dimensions $\left(L_{\mathrm{c}}\right.$ and $\left.L_{\mathrm{a}}\right)$ were calculated using the Bragg and Scherrer equations, respectively, ${ }^{40}$ which are summarized in Table S2. $\dagger$ The (002) diffraction peak exhibits a slight increase of $2 \theta$ value with an increase in carbonization temperature, and the $L_{\mathrm{c}(002)}$ and $L_{\mathrm{a}(101)}$ values show a similar tendency to $d_{002}$. The ratio of $L_{\mathrm{c}(002)}$ and $d_{002}(N=$ $\left.L_{\mathrm{c}(002)} / d_{(002))}\right)$ represents the number of the graphite layer planes, and this value increased when the heat-treated temperature increased from $600{ }^{\circ} \mathrm{C}$ to $900{ }^{\circ} \mathrm{C}$, which suggests that higher temperature could lead to more graphite layer planes and a more stable graphitic structure. ${ }^{41}$

Fig. 2d displays the Raman spectra of all the samples. The peaks at $1300 \mathrm{~cm}^{-1}$ and $1600 \mathrm{~cm}^{-1}$ can be seen significantly, which correspond to the $\mathrm{D}$ and $\mathrm{G}$ bands. The $\mathrm{D}$ band is related to structure defects, such as curved sheets and dangling bonds in the carbon structure, whereas the $\mathrm{G}$ band is generally associated with the in-plane bond-stretching motions of the pairs of $\mathrm{sp}^{2} \mathrm{C}$ atoms. ${ }^{42,43}$ The intensity ratios of the $\mathrm{D}$ and $\mathrm{G}$ bands $\left(I_{\mathrm{D}} / I_{\mathrm{G}}\right)$ can be used to examine the degree of disordering in the graphitic structure, and a large ratio corresponds to the more defects introduced by heteroatom doping and/or a less $\mathrm{sp}^{2}$ electronic configuration. ${ }^{43}$ The $I_{\mathrm{D}} / I_{\mathrm{G}}$ ratio of PAC-600, PAC-700, PAC-800, PAC-900 and DC-800 are approximately 1.13, 1.12, $1.05,1.03$ and 1.05 , respectively. The decrease in defects indicates that the carbonized samples approach a more stable state with an increase in the carbonization temperature.

The elemental compositions and bonding configurations of the as-prepared carbon materials were characterized by XPS measurements. Fig. S1a $\uparrow$ depicts the survey spectrum of the samples, where only $\mathrm{C}, \mathrm{N}$ and $\mathrm{O}$ can be found, which confirms that these carbon nanofibers are indeed $\mathrm{N}$-doped 
nanomaterials. Furthermore, the elemental distributions were also evaluated by quantitative energy dispersive X-ray spectroscopy (EDS) element mapping (Fig. S1c-e †), where the C, $\mathrm{N}$ and $\mathrm{O}$ elements were homogeneously distributed on the surface of PAC-800. The high-resolution spectrum was employed to further analyze the elemental compositions. As shown in Fig. 3a, the high-resolution $\mathrm{C}$ 1s spectrum displays three major components, corresponding to $\mathrm{C}=\mathrm{C}(284.7 \mathrm{eV}), \mathrm{C}-\mathrm{N} / \mathrm{C}-\mathrm{O}(286.1$ $\mathrm{eV})$ and $\mathrm{C}=\mathrm{N} / \mathrm{C}=\mathrm{O}(290.3 \mathrm{eV}) .{ }^{44,45}$ Similarly, the $\mathrm{O} 1 \mathrm{~s}$ spectrum is found to entail three oxygen moieties (Fig. 3b). The three major peaks at the binding energy of $530.8,532.9$ and $534.7 \mathrm{eV}$ might be assigned to $\mathrm{H}-\mathrm{O}-\mathrm{C}, \mathrm{O}-\mathrm{C}$ and $\mathrm{O}=\mathrm{C}$, respectively. ${ }^{14,46}$ For the high-resolution $\mathrm{N}$ 1s spectrum (Fig. 3c), the four subpeaks were deconvoluted, including pyridinic $\mathrm{N} 1$ at $397.3 \mathrm{eV}$, pyrrolic $\mathrm{N} 2$ at $398.6 \mathrm{eV}$, graphitic N3 at $401.4 \mathrm{eV}$ and oxidized N4 at $404.3 \mathrm{eV}^{47}$ As shown in Fig. $3 \mathrm{~d}$ and Table S3, $\dagger$ the total $\mathrm{N}$ content decreased with an increase in the carbonization temperature. However, the content of graphitic N3 and oxidized $\mathrm{N} 4$ remained unchanged, which indicates a conversion from pyridinic $\mathrm{N} 1$ and pyrrolic $\mathrm{N} 2$ to the more stable graphitic $\mathrm{N} 3$ and oxidized $\mathrm{N} 4$ upon increasing the carbonization temperature. ${ }^{48-51}$ Several research groups deemed that graphitic N3 atoms in the carbon lattice facilitate the electron transfer from the carbon electronic bands to the antibonding orbitals of oxygen, which benefits the ORR catalytic activity. ${ }^{52-54}$

Electrochemical measurements of the activated carbon catalysts were performed in an $\mathrm{O}_{2}$ or $\mathrm{N}_{2}$ saturated $0.1 \mathrm{~mol} \mathrm{~L}^{-1}$ $\mathrm{KOH}$ solution at the scan rate of $10 \mathrm{mV} \mathrm{s}^{-1}$. As shown in Fig. 4a, no evident peaks are observed in the $\mathrm{N}_{2}$-saturated $\mathrm{KOH}$ solutions; however, a well-defined cathodic oxygen reduction peak of $\mathrm{Pt} / \mathrm{C}$ and $\mathrm{PAC}-800$ at -0.12 and $-0.13 \mathrm{~V}$ vs. $\mathrm{Ag} / \mathrm{AgCl}$ is observed in the $\mathrm{O}_{2}$-saturated $\mathrm{KOH}$ solutions, respectively. To further study the electrochemical performance of the asprepared catalysts toward the ORR, LSV was conducted on a rotating disk electrode (RDE) by scanning the potential from
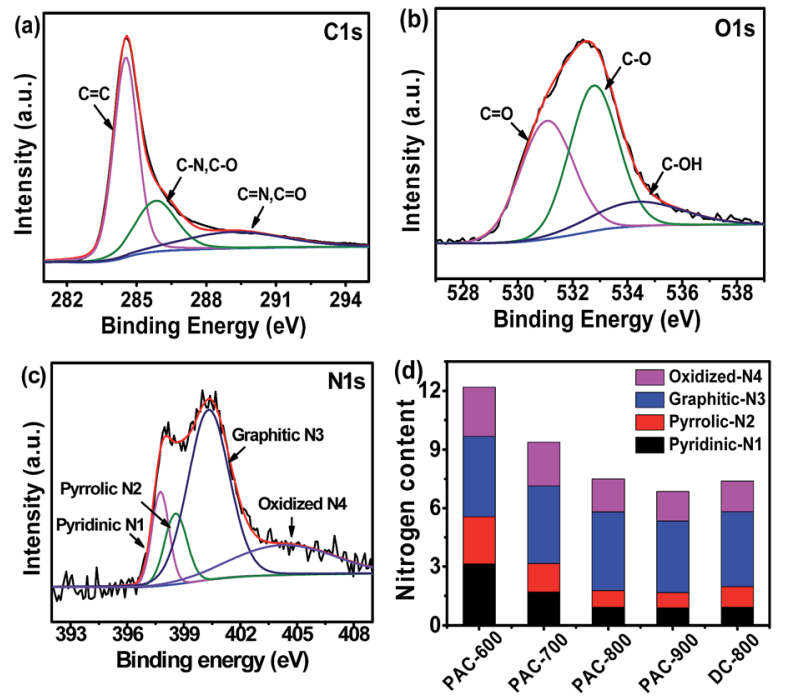

Fig. 3 High-resolution XPS scans of C 1s (a), O 1s (b) and N 1s (c) of PA800 , and the content of four types of nitrogen (d) of the CS-derived carbon materials.
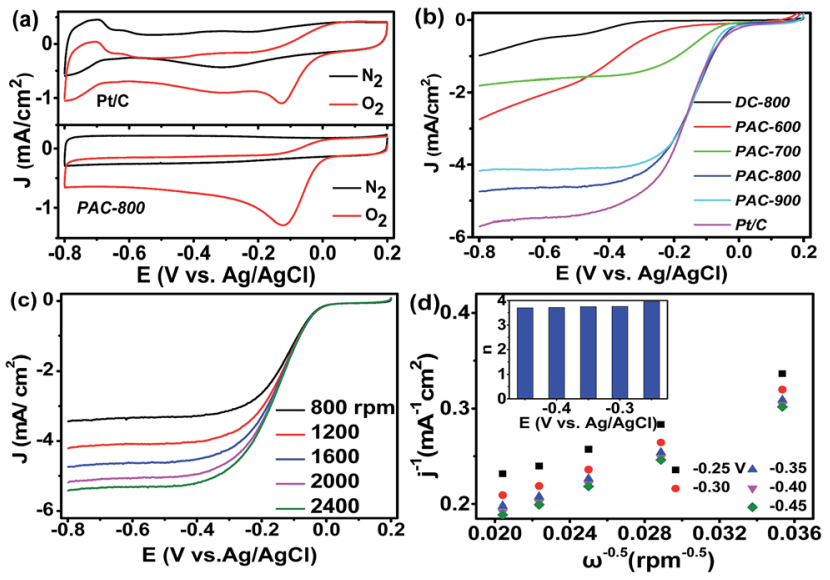

Fig. 4 (a) $\mathrm{CV}$ curves for PAC-800 and Pt/C in $\mathrm{N}_{2}$ - and $\mathrm{O}_{2}$-saturated $0.1 \mathrm{~mol} \mathrm{~L}^{-1} \mathrm{KOH}$ solutions at a scan rate of $10 \mathrm{mV} \mathrm{s}^{-1}$; (b) LSV curves for DC-800, PAC-600, PAC-700, PAC-800, PAC-900 and Pt/C in $\mathrm{O}_{2}-$ saturated $0.1 \mathrm{~mol} \mathrm{~L}^{-1} \mathrm{KOH}$ solutions at a scan rate of $10 \mathrm{mV} \mathrm{s}^{-1}$ and rotation rate of $1600 \mathrm{rpm}$; (c) LSV curves for PAC-800 in $\mathrm{O}_{2}$-saturated $0.1 \mathrm{~mol} \mathrm{~L}^{-1} \mathrm{KOH}$ solutions at a scan rate of $10 \mathrm{mV} \mathrm{s}^{-1}$ and different rotation rates from 800 to $2400 \mathrm{rpm}$; and (d) $\mathrm{K}-\mathrm{L}$ plots at different potentials for PAC-800 in $\mathrm{O}_{2}$-saturated $0.1 \mathrm{~mol} \mathrm{~L}^{-1} \mathrm{KOH}$ solutions.

+0.2 to $-0.8 \mathrm{~V}$ at a rotation rate of $1600 \mathrm{rpm}$ and scan rate of $10 \mathrm{mV} \mathrm{s}^{-1}$. As seen in Fig. 4b, PAC-800 has an onset potential of $0.03 \mathrm{~V}$, and a half-wave potential of $-0.13 \mathrm{~V}$, which are very close to those of the Pt/C. PAC-800 exhibits the most positive onset potential and the highest current density compared with the catalysts carbonized at other temperatures, which suggest that chemical activation at $800{ }^{\circ} \mathrm{C}$ can achieve the best electrochemical activity for the CS-derived activated carbon materials. Notably, PAC-800 is comparable to the biomass-derived carbon catalysts reported in the literature (Table $\mathrm{S} 4 \dagger$ ). Not only its carbon surface chemistry, but also its carbon electronic structure was changed due to the introduction of functional groups into its carbon lattice. In this regard, the doped $\mathrm{N}$ is able to create a positive charge density on the adjacent $\mathrm{C}$ atoms, which results in favourable $\mathrm{O}_{2}$ adsorption and high catalytic activity towards the ORR. ${ }^{49-51}$ Combining the physical and chemical measurements, its large surface area and abundant pore structure may also contribute to the remarkable ORR catalytic activity of PAC-800. The catalytic activity of the silk-derived activated carbon increased with an increase in pyrolysis temperature from $600{ }^{\circ} \mathrm{C}$ and $800{ }^{\circ} \mathrm{C}$, which is in accordance with the increase in surface area and pore volume. This result provides evidence that its large surface area and porous structure might be responsible for its ORR catalytic activity.

RDE measurements at different rotational speeds from 800 to $2400 \mathrm{rpm}$ were performed to further investigate the ORR performances of PAC-800. As seen in Fig. 4c, it is clear that the limiting diffusion current became larger with the increase in speed. The electron transfer numbers were analyzed on the basis of the K-L plots. As shown in Fig. 4d, in the K-L plots of PAC-800, the relationship between $j^{-1}$ and $\omega^{-1 / 2}$ is well linear between -0.25 and $-0.45 \mathrm{~V}$. According to the $\mathrm{K}-\mathrm{L}$ equation, the electron transfer number during the ORR process was calculated to be close to four (3.72-3.96), indicating that the ORR 
process occurs through a four electron transfer pathway, which is similar to that of the commercial Pt/C catalyst (Fig. S2 $\dagger$ ).

The stability and resistance to crossover effects of catalysts are very important issues for their practical application in various energy technologies. Stability and crossover were examined during the ORR process. The stability of PAC-800 was examined in an $\mathrm{O}_{2}$-saturated $0.1 \mathrm{~mol} \mathrm{~L}^{-1} \mathrm{KOH}$ solution at $1600 \mathrm{rpm}$ over $12000 \mathrm{~s}$ of continuous operation at $-0.35 \mathrm{~V} v \mathrm{~s}$. $\mathrm{Ag} / \mathrm{AgCl}$ (Fig. 5a). It can be seen that the ORR current density of the PAC-800 electrode decreased by only $6.8 \%$, but the Pt/C electrode exhibited a $30.0 \%$ decrease in current density under the same conditions. The tolerance to the methanol crossover effect is shown in Fig. 5b, and it can be seen that the catalytic current of PAC-800 for the ORR is unaffected by the addition of $1 \mathrm{~mL}$ methanol. However, a deep current decrease was observed for $\mathrm{Pt} / \mathrm{C}$ when $1 \mathrm{~mL}$ methanol was added. These results demonstrate that PAC-800 exhibits promising stability towards the ORR with a remarkable tolerance to the methanol crossover effects.

With regard to the practical application of PAC-800, its feasibility was investigated as a cathodic ORR catalyst in an aircathode single-chamber microbial fuel cell (MFC). The MFC has been intensively researched in recent years as a promising renewable energy technology for wide application, for example, electricity generation, wastewater treatment, biogas production, and pollutant removal. ${ }^{55,56}$ However, its commercial application has been hindered by the high cost of electrode materials due to the use of Pt based cathodic catalyst in its cathodes. ${ }^{57}$ Various non-noble metal and metal-free catalysts, such as transition metal macrocycles, metal oxides, and various carbon materials, have been developed to replace the Pt component. . $^{1417-20,58-61}$ The suitability of PAC-800 as a replacement for the Pt/C catalyst for MFCs was investigated by constructing a single-chamber MFC with the PAC-800 cathode. As seen in Fig. 6(a), the MFC with the PAC-800 cathodic catalyst has a maximum power density of about $800 \mathrm{~mW} \mathrm{~m}^{-2}$, which is slightly lower than that of the MFC with the $\mathrm{Pt} / \mathrm{C}$ cathodic catalyst $\left(1100 \mathrm{~mW} \mathrm{~m}^{-2}\right)$. Fig. $6 \mathrm{~b}$ shows the individual potential $v s$. current density for both the anode and cathode. For these MFCs, the anode potentials were similar; however, the cathode potentials were different, which indicates that the differences between the MFCs performances are primarily related to the different catalytic activity of the
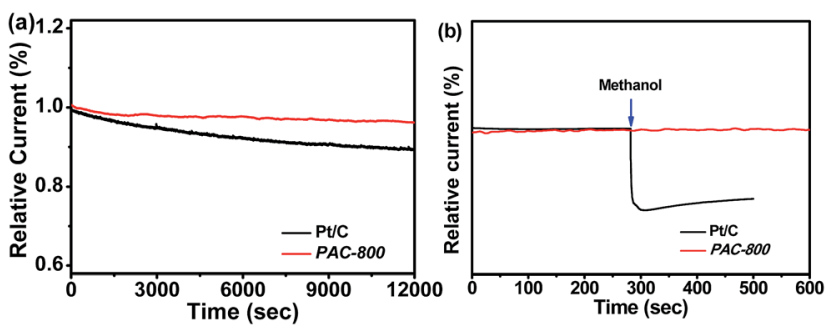

Fig. 5 (a) Chronoamperometric responses of the PAC-800 and Pt/C electrodes at $-0.35 \mathrm{~V}$ (vs. $\mathrm{Ag} / \mathrm{AgCl}$ ) in $\mathrm{O}_{2}$-saturated $0.1 \mathrm{~mol} \mathrm{~L}^{-1} \mathrm{KOH}$ solutions at a rotation rate of $1600 \mathrm{rpm}$, normalized to the initial current responses; and (b) chronoamperometric responses to the injection of $1 \mathrm{~mL}$ methanol into $\mathrm{O}_{2}$-saturated $0.1 \mathrm{~mol} \mathrm{~L}^{-1} \mathrm{KOH}$ solution at the PAC-800 and Pt/C electrodes.
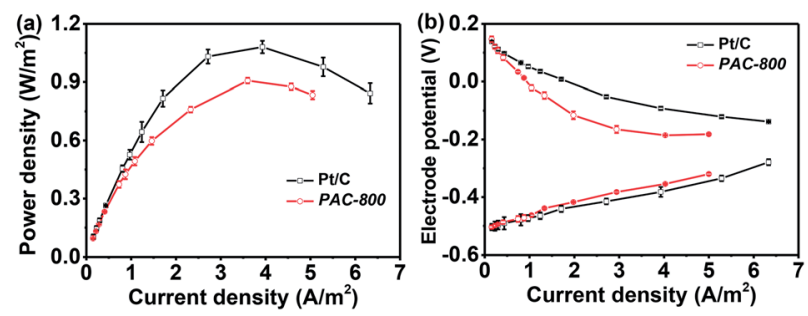

Fig. 6 (a) Polarization curves of the MFCs with PAC-800 and Pt/C cathodes; and (b) curves of individual potentials in the MFCs.

cathodic catalyst. Although the lower power density achieved from the MFC with the PAC-800 cathode is slightly lower than that of the Pt cathode, the as-prepared PCA-800 still has numerous advantages as an electrocatalyst towards ORR. The cost of PCA-800 is relatively low due to its sustainable nature, and the strategy used to produce this catalyst could be easily scaled-up because the entire process is facile.

\section{Conclusions}

In summary, we reported a CS-derived N-doped porous carbon with exceptionally high electrocatalytic activity for the ORR, which was fabricated via a facile heat treatment combined with a chemical activation procedure under mild conditions. Popular CS, which is an abundantly available and renewable biomass, acts as a single precursor for carbon as well as nitrogen in the synthetic process, eliminating the need for multiple hazardous chemicals. Its remarkable ORR catalytic activity is partially attributed to the highly positive charges on the carbon atoms, in which the electronegative nitrogen atoms are doped. Moreover, the excellent ORR catalytic activity of PAC-800 might also originate from the combined effect of its porous structure and high surface area. The prepared PAC- 800 exhibits promising stability and good tolerance to the methanol crossover effect. An MFC using PAC-800 as the cathode catalyst exhibits a good performance with a maximum power density of $800 \mathrm{~mW} \mathrm{~m}^{-2}$, which suggests that this material offers a low-cost alternative to Pt/C catalysts for microbial energy harvesting. The present study provides a new, facial and environmentally friendly approach to prepare activated carbon with high catalytic activity towards the ORR from the natural material, silk.

\section{Acknowledgements}

The present study was supported by the National Natural Science Foundation of China (Grant No. 51678162 and 41301264), the Guangdong Natural Science Funds for Distinguished Young Scholar (2014A030306033), the Guangdong Science-Technology Project (2016A020209009), and the Guangdong Academy of Sciences Funds for Innovation Driven Development (2017GDASCX-0409).

\section{Notes and references}

1 B. Zheng, J. Wang, F. B. Wang and X. H. Xia, J. Mater. Chem. A, 2014, 2, 9079-9084. 
2 Z. J. Jiang and Z. Q. Jiang, J. Mater. Chem. A, 2014, 2, 1407114081.

3 R. F. Service, Science, 2007, 315, 1488-1491.

4 J. Liang, R. F. Zhou, X. M. Chen, Y. H. Tang and S. Z. Qiao, Adv. Mater., 2014, 26, 6074-6079.

5 H. Kim, G. Jeong, Y. U. Kim, J. H. Kim, C. M. Park and H. J. Sohn, Chem. Soc. Rev., 2013, 42, 9011-9034.

6 Z. C. Zuo, W. Li and A. Manthiram, J. Mater. Chem. A, 2013, 1, 10166-10172.

7 Z. M. Luo, D. L. Yang, G. Q. Qi, J. Z. Shang, H. P. Yang and Y. L. Wang, J. Mater. Chem. A, 2014, 2, 20605-20611.

8 T. Lee, E. K. Jeon and B. S. Kim, J. Mater. Chem. A, 2014, 2, 6167-6173.

9 S. Y. Gao, H. Fan and S. X. Zhang, J. Mater. Chem. A, 2014, 2, 18263-18270.

10 M. Arenz, K. J. J. Mayrhofer, V. Stamenkovic, B. B. Blizanac, T. Tomoyuki and P. N. Ross, J. Am. Chem. Soc., 2005, 127, 6819-6829.

11 A. Morozan, B. Jousselme and S. Palacin, Energy Environ. Sci., 2011, 4, 1238-1254.

12 T. Chen and L. M. Dai, Mater. Today, 2013, 16, 272-280.

13 L. Dai, W. C. Dong, J. B. Baek and L. Wen, Small, 2012, 8, 1130-1166.

14 L. H. Zhou, P. Fu, X. X. Cai, S. G. Zhou and Y. Yuan, Appl. Catal., B, 2016, 188, 31-38.

15 F. Yang, Y. X. Tao, Y. Y. Du and R. L. Xiao, Adv. Mater. Res., 2011, 219, 331-336.

16 T. Yang, J. Liu, R. Zhou, Z. Chen, H. Xu and S. Z. Qiao, J. Mater. Chem. A, 2014, 2, 18139-18146.

17 L. H. Zhou, P. Fu, D. H. Wen, Y. Yuan and S. G. Zhou, Appl. Catal., B, 2016, 181, 635-643.

18 S. Y. Gao, K. R. Geng, H. Y. Liu, X. J. Wei, M. Zhang and P. Wang, Energy Environ. Sci., 2014, 8, 221-229.

19 Z. Y. Guo, G. Y. Ren, C. C. Jiang, X. Y. Lu, Y. Zhu and L. Jiang, Sci. Rep., 2015, 5, 17064-17070.

20 P. Chen, L. K. Wang, G. Wang, M. R. Gao, J. Ge and W. J. Yuan, Energy Environ. Sci., 2014, 7, 4095-4103.

21 S. Y. Gao, H. Fan and S. X. Zhang, J. Mater. Chem. A, 2014, 2, 18263-18270.

22 R. F. Wang, H. Wang, T. B. Zhou, J. L. Key, Y. J. Ma and Z. Zhang, J. Power Sources, 2015, 274, 741-747.

23 K. Hasanudin, P. Hashim and S. Mustafa, Molecules, 2012, 7, 9697-9715.

24 A. Nova, S. Keten, N. M. Pugno, A. Redaelli and M. J. Buehler, Nano Lett., 2010, 10, 2626-2634.

25 J. A. Kluge, O. Rabotyagova, G. G. Leisk and D. L. Kaplan, Trends Biotechnol., 2008, 26, 244-251.

26 M. Heim, D. Keer and T. Scheibel, Angew. Chem., Int. Ed., 2009, 48, 3584-3596.

27 A. D. Parkhe, S. K. Seeley, K. Gardner, L. Thompson and R. V. Lewis, J. Mol. Recognit., 1997, 10, 1-6.

28 T. Iwazaki, H. S. Yang, R. Obinata, W. Sugimoto and Y. Takasu, J. Power Sources, 2010, 195, 5840-5847.

29 T. Iwazaki, R. Obinata, W. Sugimoto and Y. Takasu, Electrochem. Commun., 2009, 11, 376-378.

30 Q. Wang, R. Y. Zhang, Y. Wu, H. Zhu, J. Zhang and M. Du, RSC Adv., 2016, 6, 34219-34224.
31 C. Kim, Y. I. Jeong, B. T. N. Ngoc, K. S. Yang, M. Kojima, Y. A. Kim, M. Endo and J. W. Lee, Small, 2007, 3, 91-95.

32 M. R. Khan, Y. Gotoh, H. Morikawa, M. Miura, Y. Fujimori and M. Nagura, Carbon, 2007, 45, 1035-1042.

33 Z. H. Hu and E. R. Vansant, J. Colloid Interface Sci., 1995, 176, 422-431.

34 E. Gnozalez-Serrano, T. Crodero, J. Rodriguez-Mirasol and J. J. Rodriguez, Int. Eng. Chem. Res., 1997, 36, 4832-4838.

35 Z. R. Yue, C. L. Mangun and J. Economy, Carbon, 2002, 40, 1181-1191.

36 W. J. Qian, F. X. Sun, Y. H. Xu, L. H. Qiu, C. H. Liu and S. D. Wang, Energy Environ. Sci., 2014, 7, 379-386.

37 Y. S. Yun, S. Y. Cho, J. Shim, B. H. Kim, S. Chang and S. J. Baek, Adv. Mater., 2013, 2, 1993-1998.

38 X. J. Liu, W. J. Zhou, L. J. Yang, L. G. Li, Z. Y. Zhang and Y. T. Ke, J. Mater. Chem. A, 2015, 3, 8840-8846.

39 J. Hou, C. Cao, F. Idrees and X. Ma, ACS Nano, 2015, 9, 556564.

40 C. Kim, S. H. Park, J. I. Cho, Y. D. Lee, T. J. Park, W. J. Lee and K. S. Yang, J. Raman Spectrosc., 2004, 35, 928-933.

41 S. Y. Cho, Y. S. Yun, S. Lee, D. Jang, K. Y. Park, J. K. Kim, B. H. Kim, K. Kang, D. L. Kaplan and H. J. Jin, Nat. Commun., 2015, 6, 7145-7152.

42 X. J. Liu, Y. C. Zhou, W. J. Zhou, L. G. Li, S. B. Huang and S. W. Chen, Nanoscale, 2015, 7, 6136-6142.

43 Y. Chen, J. Li, T. Mei, X. Hu, D. Liu and J. Wang, J. Mater. Chem. A, 2014, 2, 20714-20722.

44 X. J. Liu, W. J. Zhou, L. J. Yang, L. G. Li, Z. Y. Zhang and Y. T. Ke, J. Mater. Chem. A, 2015, 3, 8840-8846.

45 T. I. T. Okpalugo, P. Papakonstantinou, H. Murphy, J. McLaughlin and N. M. D. Brown, Carbon, 2005, 43, 1531561.

46 V. Datsyuk, M. Kalyva, K. Papagelis, J. Parthenios, D. Tasis and A. Siokou, Carbon, 2008, 46, 833-840.

47 K. Zhou, W. J. Zhou, X. J. Liu, Y. Wang, J. Q. Wan and S. W. Chen, ACS Appl. Mater. Interfaces, 2014, 6, 1491114918.

48 K. P. Gong, F. Du, Z. H. Xia, M. Durstock and L. M. Dai, Science, 2009, 323, 760-764.

49 L. Y. Feng, Y. Y. Yan, Y. G. Chen and L. J. Wang, Energy Environ. Sci., 2011, 4, 1892-1899.

50 H. R. Byon, J. Suntivich and Y. Shao-Horn, Chem. Mater., 2011, 23, 3421-3428.

51 K. R. Lee, K. U. Lee, J. W. Lee, B. T. Ahn and S. I. Woo, Electrochem. Commun., 2010, 12, 1052-1055.

52 N. P. Subramanian, X. G. Li, V. Nallathambi, S. P. Kumaraguru, H. Colon-Mercado, G. Wu, J. W. Lee and B. N. Popov, J. Power Sources, 2009, 188, 38-44.

53 P. Wang, Z. K. Wang, L. X. Jia and Z. L. Xiao, Phys. Chem. Chem. Phys., 2009, 11, 2730-2740.

54 H. Kim, K. Lee, S. I. Woo and Y. Jung, Phys. Chem. Chem. Phys., 2011, 13, 17505-17510.

55 B. E. Logan and J. M. Regan, Environ. Sci. Technol., 2006, 40, 5172-5180.

56 W. W. Li, H. Q. Yu and Z. He, Energy Environ. Sci., 2014, 7, 911-924.

57 B. E. Logan, Appl. Microbiol. Biotechnol., 2010, 85, 1665-1671. 
58 X. W. Liu, W. W. Li and H. Q. Yu, Chem. Soc. Rev., 2014, 43, 60 L. Zhang, C. S. Liu, L. Zhuang, W. S. Li, S. G. Zhou and 7718-7745.

J. J. Zhang, Biosens. Bioelectron., 2009, 24, 2825-2829.

59 Y. Yuan, B. Zhao, Y. W. Jeon, S. G. Zhong and S. Kim, 61 X. Zhang, X. Xia, I. Ivanov, X. Huang and B. E. Logan, Bioresour. Technol., 2011, 102, 5849-5854.

Environ. Sci. Technol., 2014, 48, 2075-2081. 